\title{
НЕЙРОННЫЕ СВЕРТОЧНЫЕ СЕТИ, КАК УНИВЕРСАЛЬНЫЙ ИНСТРУМЕНТ РАСПОЗНАВАНИЯ ГРАФИЧЕСКИХ ОБЪЕКТОВ
}

\section{NEURAL CONVENTIONAL NETWORKS AS A UNIVERSAL TOOL FOR RECOGNIZING GRAPHIC OBJECTS}

M. Rudenko

Yu. Golodkov

A. Golodkova

Summary. The article discusses the fundamental methods of the most actively developing and widely demanded area of information technology associated with the identification and recognition of graphic images from static images, as well as video.

Keywords: machine intelligence, personality identification, neural convolutional networks, verification.

\author{
Руденко Максим Борисович \\ K.т.н., nрофессор, Восточно-Сибирский институт \\ МВД России, г. Иркутск \\ rudenko@inbox.ru \\ Голодков Юрий Эдуардович \\ К.т.н., дочент, Иркутский национальный \\ исследовательский технический университет \\ yrg27@mail.ru \\ Голодкова Александра Валерьевна \\ Старший преподаватель, Иркутский \\ национальный исследовательский технический \\ университет \\ alex17-27@mail.ru
}

Аннотация. В статье рассматриваются основополагающие методы наиболее активно развивающегося и широко востребованного направления информационных технологий, связанного с выявлением и распознаванием графических образов со статических изображений, а также видеоряда.

Ключевые слова: машинный интеллект, идентификация личности, нейронные сверточные сети, верификация.

а получено (выделено) специалистами. Поэтому, для существующего изображения определяют вектор признаков и совершают верификацию с вектором признаков изображений, хранящихся в базе данных. Таким образом, реализуется процесс идентификации личности.

При работе с потоком видеоинформации идентификация человека по изображению лица, силуэту, походке осуществляется после того, как будет установлено наличие необходимого графического объекта на изображении. То есть по видеоряду изображений сначала осуществляется обнаружение и выделение необходимого графического объекта, а затем выделяется необходимый вектор признаков для идентификации личности.

Работы по обнаружению лица человека на графическом изображении проводились еще в 70-х годах прошлого столетия. Хороший результат был получен при использовании признаков Хаара. Признаки Хаара признаки цифрового изображения, которые эффективно использовались в распознавании образов в первом детекторе лиц, работающем в режиме реального времени. Своим названием они обязаны сходством с вейвлетами Хаара. Признаки или примитивы (маски) Хаара представляют собой прямоугольники с областями черного и белого цветов (рис. 1). 


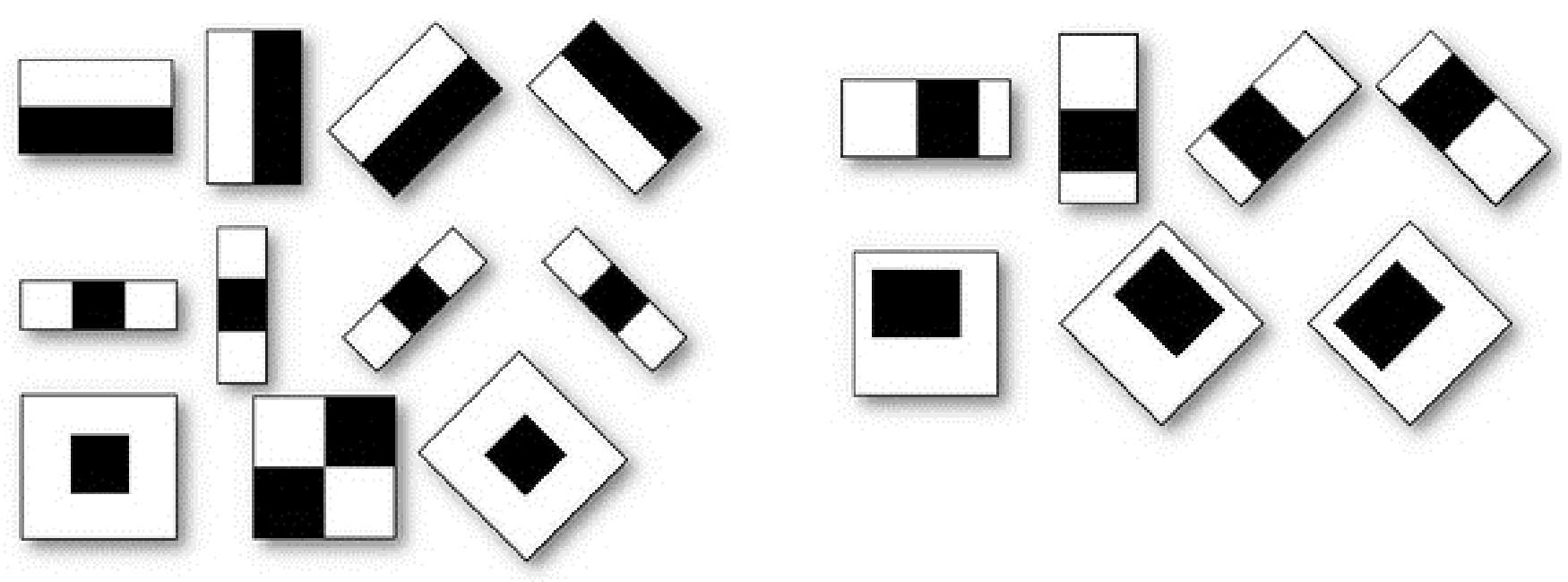

Рис. 1. Примеры примитивов (масок) Хаара

\begin{tabular}{|c|c|c|c|c|c|}
\hline 131 & 2 & 4 & 33 & 5 & 36 \\
\hline 12 & 26 & 9 & 10 & 29 & 25 \\
\hline 13 & 17 & 21 & 22 & 20 & 18 \\
\hline 24 & 23 & 15 & 16 & 14 & 19 \\
\hline 30 & 8 & 28 & 27 & 11 & 7 \\
\hline 1 & 35 & 34 & 3 & 32 & 6 \\
\hline
\end{tabular}

\begin{tabular}{|c|c|c|c|c|c|}
\hline 31 & 33 & 37 & 70 & 75 & 111 \\
\hline 43 & 71 & 84 & 127 & 161 & 222 \\
\hline 56 & 101 & 135 & 200 & 254 & 333 \\
\hline 80 & 148 & 197 & 278 & 346 & 444 \\
\hline 110 & 186 & 263 & 371 & 450 & 555 \\
\hline 111 & 222 & 333 & 444 & 555 & 666 \\
\hline
\end{tabular}

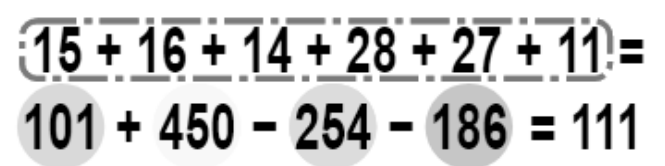

Рис. 2. Пример приведения матрицы чисел к интегральному виду

При наложении примитивов на черно-белое изображение можно выявить наличие и местоположение лица человека на нем. Размеры и местоположение примитивов при наложении на изображение последовательно меняются. Например, при рассмотрении лица человека в черно-белом формате можно отметить, что области глаз человека, ямки на щеках и подбородке, ноздри будут выглядеть более темными, чем лоб, щеки, кончик носа и подбородок. Совпадение темных и светлых областей с изображением позволяет выявить наличие искомого графического объекта на изображении.
Быстродействие алгоритма достигается переведением матрицы яркости черно-белого изображения в интегральную форму, что позволяет сократить время работы алгоритма (рис. 2).

Приведение значения яркости матрицы черно-белого изображения в интегральную форму способствует переходу к более крупным формам отображения графической информации, определением среднего значения яркости этих форм, а также уменьшению количества дальнейших вычислений. 


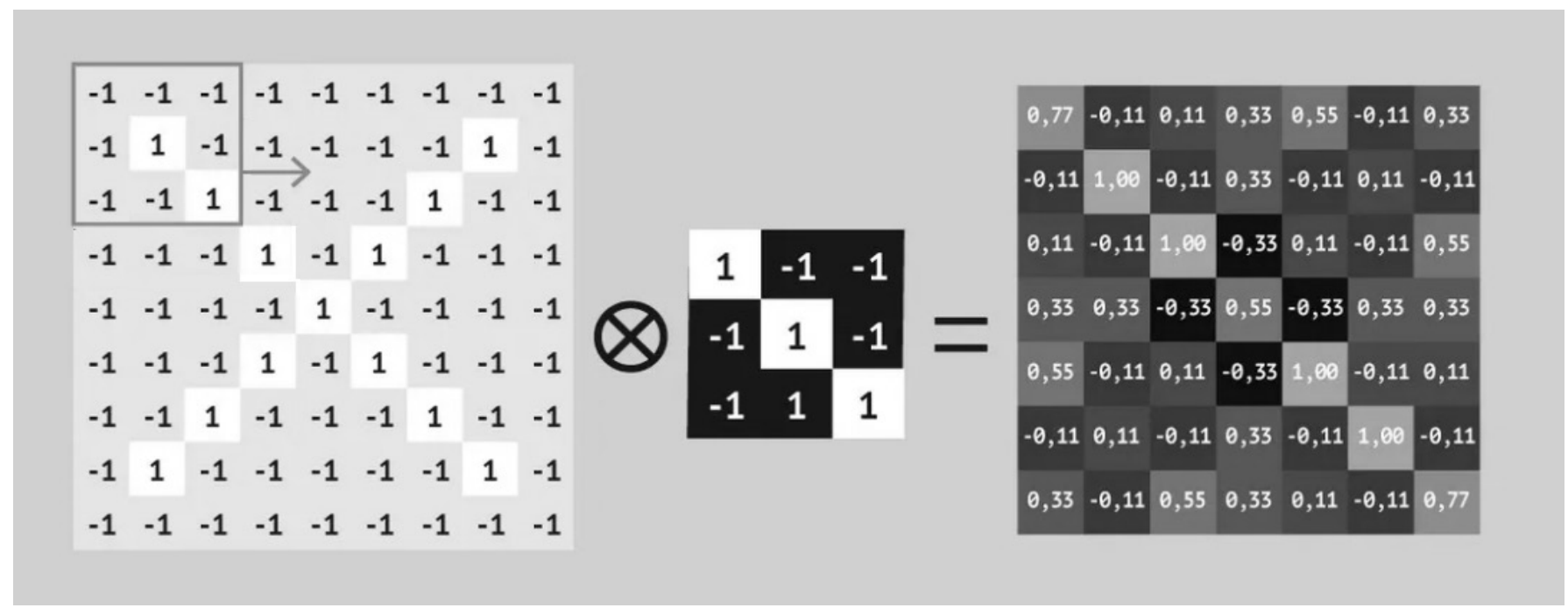

Рис. 3. Пример свертки изображения с использованием диагональной маски Хаара

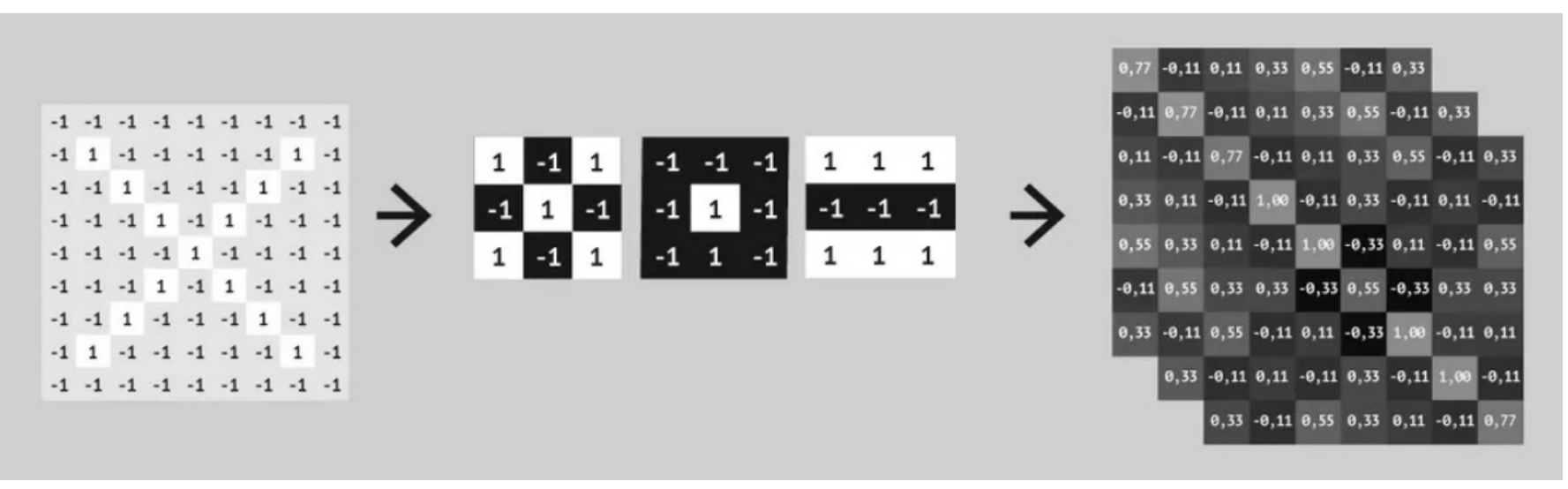

Рис. 4. Пример создания карт признаков для использования в сверточной нейросети

На рис. 2 можно видеть, каким образом осуществляется интегральное преобразование со значениями матрицы чисел. Аналогичным образом выполняются действия со значениями матрицы яркости черно-белого изображения. Для определения среднего значения яркости выделенного прямоугольника остается выполнить операции всего с четырьмя числами.

В 2001 году свой подход для решения задач идентификации человека по изображению лица предложили Пол Виола и Майкл Джонс. Их подход заключался в использовании метода каскадного бустинга (Ada Boost) при работе с набором примитивов. При каскадном бустинге изображение образа подвергается свертке с использованием масок Хаара [6,7] (рис. 3,4).

Метод каскадного бустинга используется, как при обучении системы по распознаванию образов на су- ществующих примерах (например, лица человека), так и при идентификации личности на изображении.

При обучении системы нейронная сеть определяет, какие паттерны являются более «сильными», наиболее часто применяются системой при опознании образов, имеют больший вес в системе, а какие - меньший.

Задача алгоритма AdaBoost - выбрать те примитивы, которые наиболее эффективно выделяют данный объект.

На основе таких классификаторов с отобранными наиболее эффективными примитивами строится каскад (рис. 5,6). Каждый последующий элемент каскада имеет более жёсткие условия успешного прохождения, чем предыдущий (используется больше примитивов), тем самым до конца доходят только самые «правильные». 


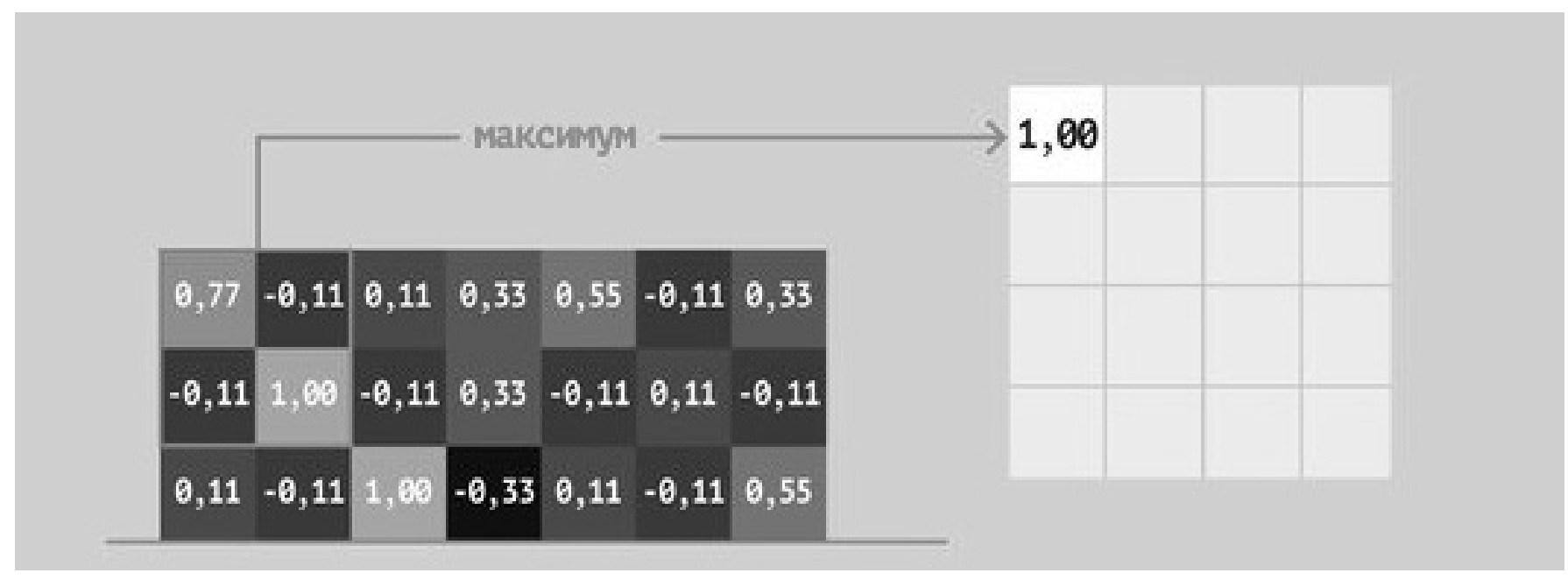

Рис. 5. Пример уменьшения размеров карт

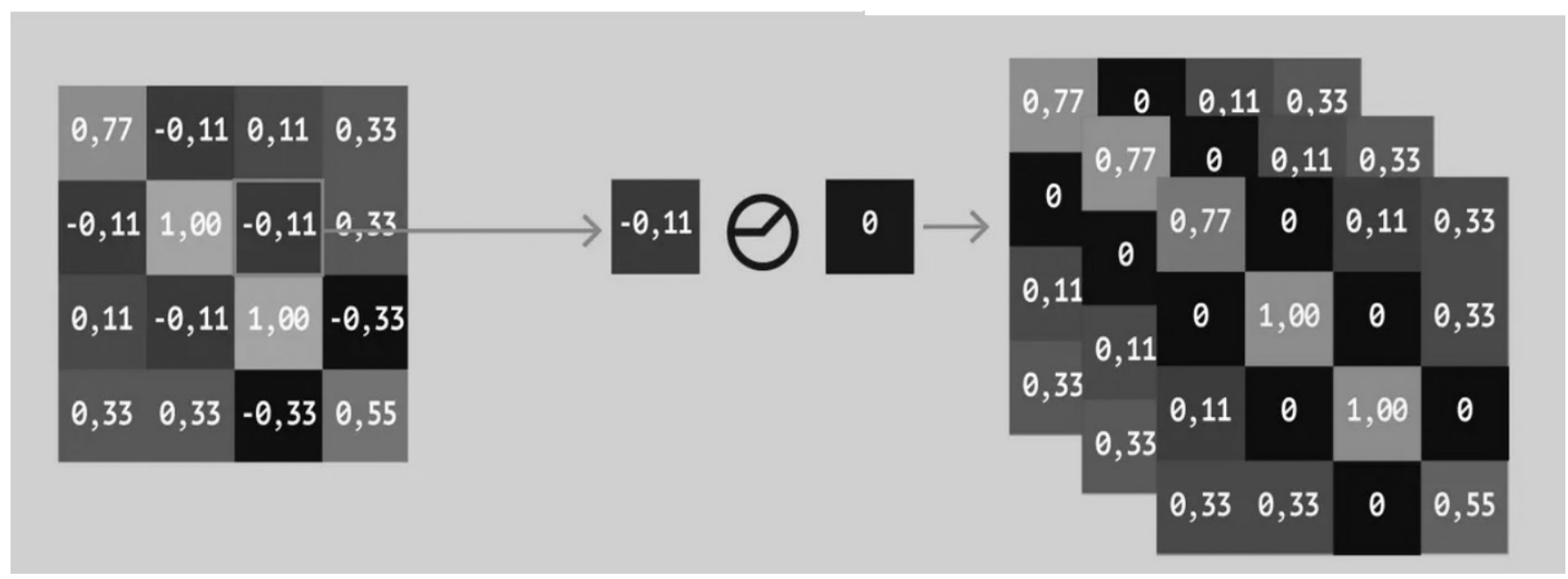

Рис. 6. Пример приведения значений матрицы только к положительным значениям

Влияние масок на точность системы распознавания образов настраивается программно через весовые коэффициенты передачи сигналов между уровнями нейронной сети. Большое значение имеет настройка весовых коэффициентов для «слабых» паттернов, которые вносят свой вклад в уточнение распознавания образов.

Таким образом, использование каскадов AdaBoost для получения свертки изображения оказывает усиливающий эффект на точность работы нейронной сверточной сети по идентификации человека по его изображению.

Свертка изображения также позволяет выделить необходимый вектор признаков и сократить время обработки графической информации.
Последующая идентификация человека по его графическому образу (изображению лица, фигуры, походке, форме и отпечатков ладони, пальцев рук, радужки глаз) сводится к реализации процесса верификации, то есть сравнении вектора признаков, полученных системой с выделенного графического образа (рис. 7) с признаками вектора образа человека, хранящегося в базе данных.

Подходы в распознавании графических образов человека можно рассматривать как универсальные (существуют и специализированные методы) и во многом определяются способностью системы самонастраиваться по имеющимся примерам графических изображений.

Таким образом, работа систем распознавания графических образов может быть направлена на решение 


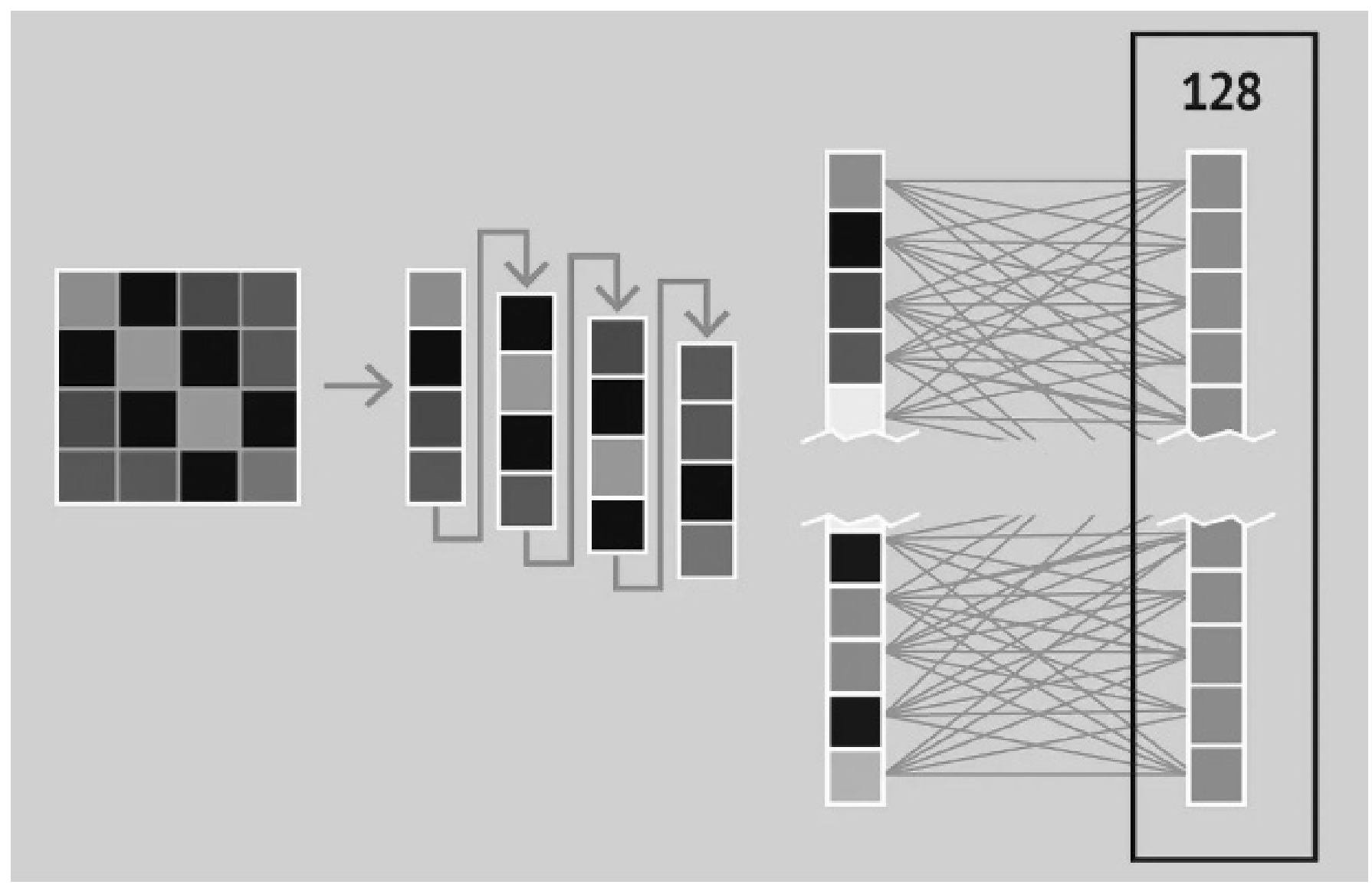

Рис. 7. Пример получения полносвязной сети, содержащей вектор признаков

не только задач идентификации человека системами видеонаблюдения, но и использоваться в военных целях для обнаружения и распознавания техники противника, для выявления признаков заболеваний по анализу всевозможной графической информации, получаемой в медицинских целях (Рентген-снимки, снимки УЗИ, МСКТ, снимки, полученные микроскопическими методами и т.д.), выявления нарушений ПДД на дорогах (переход дороги на красный свет или в неположенном месте, неразрешенные формы использования сотовой связи в движении и т.п.), определения запрещенных к перевозке предметов в багаже пассажиров, различных грузов транспортных средств, содержания контейнеров, при экспертизе веществ, материалов и изделий, определении эмоций человека (ответная реакция на раздражители, предлагаемые товары и услуги), сервисы в он-лайн образовании (контроль направленности взгляда, оценка эмоций), распознавании различных видов флоры и фауны, физических процессов, протекающих в условиях жизни Земли и космоса, и так далее, в общем на работу с любыми графическими объектами, которые визуально оценивает человек для принятия каких-либо решений. Спектр применения нейронных сверточных сетей сегодня находит все более широкое применение в разных областях науки и техники.

\section{ЛИТЕРАТУРА}

1. Программно-аппаратный комплекс, предназначенный для обучения и (или) дообучения алгоритмов обработки аэрокосмических изображений местности с целью обнаружения, локализации и классификации до типа авиационной и сухопутной техники: пат. // Балакчин В.С., Балакчина А.В., Гасникова Е.В и др. Тип: патент 2747044 C1 Рос. Федерация. № 2020119638/ Балакчин В.С., Балакчина А.В., Гасникова Е.В. и др.; заявл. 15.06.2020; опубл.23.04.2021, Бюл. № 12.13 с.

2. Программно-аппаратный комплекс, предназначенный для обучения и (или) дообучения алгоритмов обработки аэрофотоснимков видимого и дальнего инфракрасного диапазонов с целью обнаружения, локализации и классификации строений вне населенных пунктов: пат. 2747214 С1 Рос. Федерация. № 2020119318 / Балакчин В.С., Балакчина А.В., Гасникова Е.В. и др.; заявл. 06.10.2020; опубл. 04.09.2021, Бюл. № 13.10 с. 
3. Брилюк Д.В., Старовойтов В.В. Распознавание человека по изображению лица нейросетевыми методами.— Минск, 2002. — 54 с. (Препринт / Ин-т техн. кибернетики НАН Беларуси; № 2).

4. Использование каскада Хаара для сравнения изображений [Электронный ресурс] URL: https://habr.com/ru/post/198338/ (дата 06ращения: 02.09.2021)

5. Визуализация каскадов Хаара [Электронный ресурс] URL: https://habr.com/ru/post/504288/ (дата обращения: 02.09.2021)

6. На лице написано: как работает компьютерное распознавание лиц [Электронный ресурc] URL: https://www.popmech.ru/technologies/402352-na-licenapisano-kak-rabotaet-kompyuternoe-raspoznavanie-lic/ (дата обращения: 02.09.2021)

7. Детект объектов на изображении [Электронный ресурc] URL: https://habr.com/ru/post/67937/ (дата обращения: 02.09.2021)

\section{๑ Руденко Максим Борисович ( rudenko@inbox.ru ),}

Голодков Юрий Эдуардович ( yrg27@mail.ru ), Голодкова Александра Валерьевна ( alex17-27@mail.ru ).

Журнал «Современная наука: актуальные проблемы теории и практики»

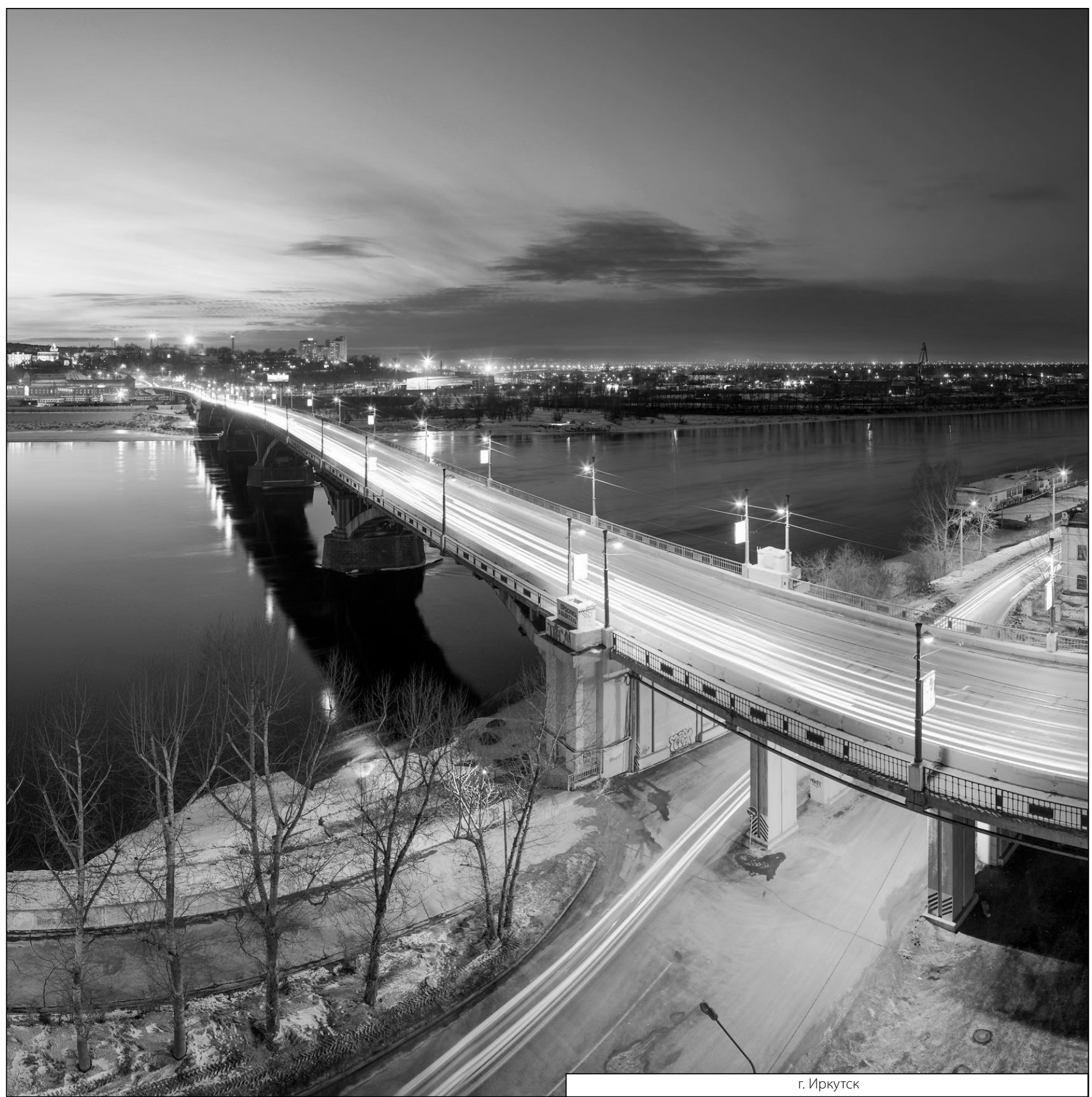

